\title{
Estudio de una fundición nodular mediante mecánica de la fractura ${ }^{(\bullet)}$
}

\author{
J. Fernández-Carrasquilla* y R. Ríos**
}

\begin{abstract}
Resumen Se estudia la tenacidad a la fractura de fundiciones de grafito nodular con diferentes matrices y tamaños de celdilla eutéctica. También se estudian las propiedades de tracción, dureza y tenacidad al impacto. Los resultados experimentales se comparan con los mismos parámetros determinados en acero al silicio de composición química similar a la de la matriz de la fundición. El posterior estudio de las superficies de fractura permite establecer los mecanismos de rotura. El análisis conjunto de los resultados mecánicos y de los estudios fractográficos permiten establecer la influencia del grafito sobre las diversas propiedades mecánicas de la fundición así como sobre los micromecanismos de fractura.
\end{abstract}

Palabras clave Tenacidad a la fractura. Propiedades mecánicas. Fundición de grafito nodular. Acero al silicio. Micromecanismos de fractura.

\section{A fracture mechanics study of nodular iron}

\begin{abstract}
In the present investigation, nodular graphite cast iron fracture toughness with different matrixes and eutectic cell sizes is studied. Properties of tensile strength, hardness and impact toughness are also studied. The experimental data are compared to the same determined parameters in silicon steel with a chemical composition similar to that of the cast iron matrix. A subsequent study of the crack surfaces enables us to establish fracture mechanisms. The joint analysis of the mechanical results and of the fractographic studies allows us to establish the influence of graphite on the different mechanical properties of cast iron and on fracture micromechanisms as well.
\end{abstract}

Keywords Fracture toughness. Mechanical properties. Nodular cast iron. Silicon steel. Fracture micromechanisms.

\section{INTRODUCCIÓN}

El propósito de este trabajo es determinar el efecto de los cambios de microestructura sobre las propiedades mecánicas y sobre los micromecanismos de fractura de una fundición nodular. Para ello se empleó fundición nodular y acero de composición química similar a la de la matriz de la fundición. Con objeto de estudiar el efecto del posible diferente tamaño de celda y de los posibles cambios en tamaño, forma y distribución de los nódulos de grafito sobre las propiedades mecánicas, se empleó fundición nodular solidificada a diferente velocidad.

Se fabricaron bloques escalonados cuya sección presenta espesores de 14 y $50 \mathrm{~mm}$ mediante colada en moldes de arena; sabiendo que la reducción de espesor de la fundición, al verse incrementada la velocidad de solidificación, produce afino de la microestructura de la matriz.
Para investigar la influencia de la microestructura de la matriz también se trataron térmicamente varias probetas extraídas de la sección gruesa de la fundición, obteniéndose en un caso matriz ferrítica por medio de un ciclo especial de recocido, que consistió en austenización a $900^{\circ} \mathrm{C}$ y enfriamiento lento hasta justo por debajo de la temperatura crítica, seguido de un prolongado empapado (soaking) y enfriamiento en el horno y cuatro estructuras de martensita revenida mediante temple en aceite desde $900^{\circ} \mathrm{C}$ con posteriores revenidos a 200, 350, 500 y $650^{\circ} \mathrm{C}$. Tanto la duración de la austenización como la del revenido fue de $1 \mathrm{~h}$.

Con objeto de obtener datos utilizables en el estudio del comportamiento a la fractura de la fundición, se prepararon muestras de acero de composición similar a la de la matriz de aquélla (Tabla I). El acero utilizado se fabricó en un horno de inducción y después de solidificar fue recocido a

(•) Trabajo recibido el día 17 de noviembre de 1997 y aceptado en su forma final el 1 de julio de 1999.

$\left(^{*}\right)$ Dpto. de Ingeniería Mecánica, Energética y de Materiales. Universidad Pública de Navarra. Campus de Arrosadía, s/n. 31006 Pamplona, Navarra (España).

(**) Dpto. de Ciencia y Tecnología de Materiales y Fluidos. Centro Politécnico Superior. María de Luna, 3.50015 Zaragoza (España). 
Tabla I. Composición química de los materiales (\% en peso)

Table I. Chemical composition of materials (\% weight)

\begin{tabular}{lcc}
\hline Elemento (\%) & Fundición nodular & Acero \\
\hline Carbono & 3,20 & 0,49 \\
Silicio & 2,04 & 2,10 \\
Manganeso & 0,10 & 0,52 \\
Azufre & 0,008 & 0,023 \\
Fósforo & 0,016 & 0,037 \\
Cobre & 0,37 & 0,047 \\
Magnesio & 0,043 & \\
\hline
\end{tabular}

$950^{\circ} \mathrm{C}$ durante $3 \mathrm{~h}$ y enfriado en horno hasta $250^{\circ} \mathrm{C}$ durante $60 \mathrm{~h}$. Se obtuvieron estructuras de martensita revenida en el acero para poder compararlas con las estructuras de la fundición tratada térmicamente. Los ciclos de tratamiento térmico fueron similares a los utilizados con las probetas de fundición endurecida, es decir, temple desde $900{ }^{\circ} \mathrm{C}$ seguido de revenido a $200,350,500$ y $650^{\circ} \mathrm{C}$.

Se prepararon muestras por duplicado de ambos materiales, fundición y acero, tanto de las probetas en estado de moldeo como de las tratadas térmicamente. En primer lugar, se extrajeron probetas de fundición de las secciones gruesa y delgada y se mecanizaron directamente para producir probetas de tenacidad con estructura de moldeo. Más tarde, en función de los resultados, se procedió a extraer fragmentos de la sección gruesa de la fundición para su posterior tratamiento térmico y mecanizado.

\section{MATERIALES, TRATAMIENTOS Y ENSAYOS}

La figura 1 es un croquis en el que se indican las zonas de donde se extrajeron las muestras, así como sus referencias NG (nodular gruesa) y ND (nodular delgada).

A continuación se da una relación de las probetas extraídas de las dos clases de material con sus referencias y tratamientos térmicos.

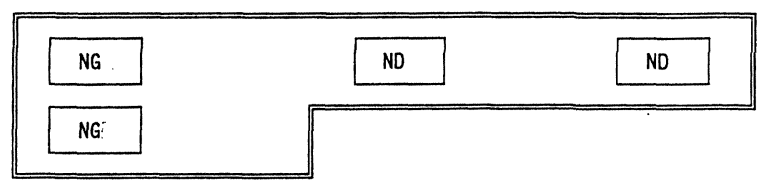

Figura 1. Bloque de diferente espesor. NG: Fundición nodular, sección gruesa. ND: Fundición nodular sección delgada.

Figure 1. Block of different thickness. NG: Nodular iron, thick section. ND: thin section.

\section{Acero}

1. Temple desde $900{ }^{\circ} \mathrm{C}$ en aceite y posterior revenido a $200^{\circ} \mathrm{C}$.

2. Id. revenido a $350^{\circ} \mathrm{C}$.

3. Id. revenido a $500^{\circ} \mathrm{C}$.

4. Id. revenido a $650^{\circ} \mathrm{C}$.

5. Austenización a $900{ }^{\circ} \mathrm{C}$, enfriamiento lento por debajo de $A_{1}$, mantenimiento prolongado y enfriamiento en el horno.

6. Condición de moldeo y posterior recocido.

\section{Fundición nodular}

7. Temple desde $900{ }^{\circ} \mathrm{C}$ en aceite y posterior revenido a $200^{\circ} \mathrm{C}$.

8. Id. revenido a $350^{\circ} \mathrm{C}$.

9. Id. revenido a $500^{\circ} \mathrm{C}$.

10. Id. revenido a $650^{\circ} \mathrm{C}$.

11. Austenización a $900^{\circ} \mathrm{C}$, enfriamiento lento por debajo de $A_{1}$, mantenimiento prolongado y enfriamiento en el horno.

12. Sin tratamiento. Condición de moldeo. Probetas extraídas de la sección delgada de la fundición nodular.

13. Sin tratamiento. Condición de moldeo. Probetas extraídas de la sección gruesa de la fundición nodular.

Los ensayos se realizaron según norma ASTM E 399-90 para el análisis elasto-lineal y según norma ASTM E 813-89 para el elasto-plástico. La geometría seleccionada para las probetas fue la de flexión en tres puntos con una entalla (SENB, Single Edge Notched Bend).

El preagrietamiento se realizó en una máquina servohidráulica de ensayos bajo condición de doblado en tres puntos. Se utilizaron galgas extensométricas de desplazamiento con el fin de evaluar $J$ como el área bajo la curva carga-desplazamiento. Los ensayos de tracción se realizaron según norma EN 10002/1 sobre probetas Hounsfield N-13 extraídas de los fragmentos que resultaron de romper las probetas SENB en los ensayos de tenacidad.

El ensayo Charpy se realizó según norma UNE 36-403-81 y proporcionó los datos de resiliencia de las probetas que fueron ensayadas a cuatro temperaturas diferentes: $26,-10,-30$ y $-60^{\circ} \mathrm{C}$. Las probetas utilizadas en este tipo de ensayo tenían una longitud de $55 \mathrm{~mm}$, una sección cuadrada de 10 $\mathrm{mm}$ de lado, y presentaban una entalla en $\mathrm{V}$ de 2 $\mathrm{mm}$ de profundidad. 
Se determinó la dureza de todas las muestras de acero y de fundición en sus diferentes estados según las normas UNE 7-422-85 y UNE 7-053-73.

Para el estudio metalográfico se utilizó un reactivo Nital-2. Las celdas eutécticas, que están formadas por los nódulos de grafito rodeados de su halo correspondiente, se apreciaron claramente utilizando un reactivo cuya composición fue: alcohol etílico: $20 \mathrm{cc}$, cloruro cúprico: $4 \mathrm{~g}$, ácido clorhídrico: $20 \mathrm{cc}$, agua: $40 \mathrm{cc}$. La valoración del tamaño, forma y distribución del grafito se efectuó según la norma UNE 36117 usando un equipo de análisis de imagen y observando veinte campos de área igual a $0,51 \mathrm{~mm}^{2}$.

Una vez rotas las probetas utilizadas en los ensayos de tenacidad, se seccionaron con objeto de extraer la porción que contenía a la superficie de fractura y poder observarla directamente en un microscopio electrónico de barrido. El examen fractográfico se concentró en la región central de la superficie de fractura por ser el área en la que prevalecen las condiciones de deformación plana.

\section{RESULTADOS EXPERIMENTALES}

Los resultados experimentales se ofrecen en las tablas I a IX.

Las muestras de acero al silicio en condición de temple y revenido a 200 y a $350^{\circ} \mathrm{C}$ no se sometieron a ensayo de tracción debido a la gran dificultad para mecanizar las probetas Hounsfield N.13 de pequeño tamaño.

Muro et al.$^{[1]}$ realizaron trabajos preliminares de determinación de tenacidad de fractura de la fundición nodular utilizada en esta investigación con probetas de dos geometrías (DENT y SENB) y tomando como base los resultados obtenidos, se decidió realizar ensayos basados en las normas ASTM E 399 y ASTM E 813 utilizando probetas SENB.

En la figura 2 se muestra el efecto de la temperatura en las propiedades mecánicas que se comentará en el apartado siguiente.

En la figura 3 se muestran las micrografías correspondientes a las microestructuras del acero, $y$ en la figura 4 las correspondientes a la fundición (Tabla VII).

Las figuras 5 y 6 muestran, respectivamente, el aspecto de la superficie de fractura de las muestras de acero al silicio y de las de fundición nodular ensayadas según norma ASTM E- 399 y observadas con el microscopio electrónico de barrido.

\section{DISCUSIÓN DE LOS RESULTADOS}

En la tabla VI aparecen los datos relativos a la fundición en condición de moldeo; su examen metalográfico muestra que es perlítica y con los nódulos de grafito rodeados por ferrita dando la típica estructura de "ojo de buey" de las fundiciones nodulares. También se puede apreciar que una disminución del espesor del bloque de fundición produce una ligera disminución del tamaño de celda eutéctica debido a la mayor velocidad de enfriamiento y que apenas influye en el tamaño de los nódulos de grafito que se mantiene prácticamente igual a 5 en ambas. Debido a estos resultados y a que la influencia del tamaño de celda eutéctica en la resistencia, límite elástico, alargamiento y dureza no es apreciable, se decidió continuar el estudio dando tratamiento térmico solamente a las probetas extraídas de la sección gruesa de la fundición
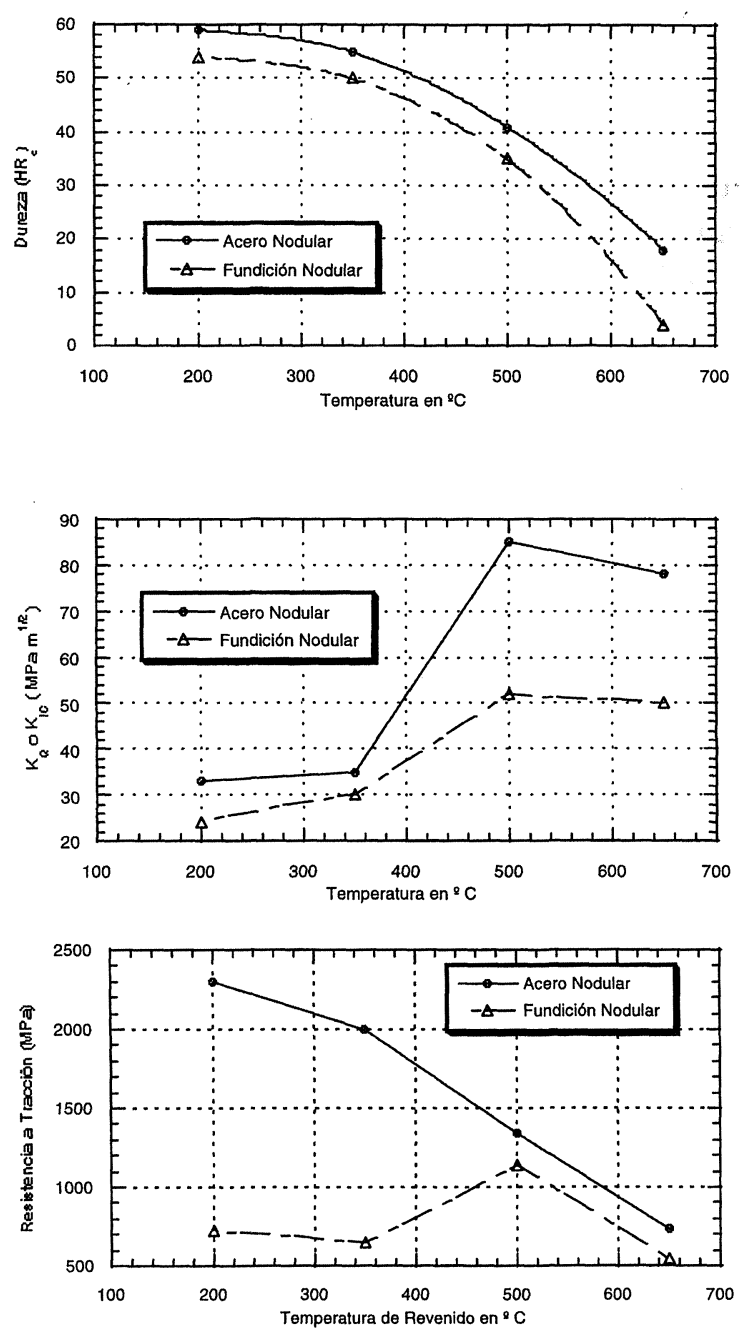

Figura 2. Efecto de la temperatura en las propiedades mecánicas.

Figure 2. Effect of temperature on mechanical properties. 
Tabla II. Resultados de los ensayos de tracción Table II. Tensile tests results

\begin{tabular}{cccc}
\hline Ref. & $R_{\mathrm{m}}$ & $R_{0,2}$ & $A_{\mathrm{t}}$ \\
& $(\mathrm{MPa})$ & $(\mathrm{MPa})$ & $(\%)$
\end{tabular}

\begin{tabular}{llll}
\hline Acero & & & \\
\hline & & & \\
$1^{*}$ & 2.300 & 1.750 & - \\
$2^{*}$ & 2.000 & 1.700 & - \\
& & & 3,9 \\
3 & $1.310,1$ & 850,3 & 14,4 \\
$3 \mathrm{~b}$ & $1.371,7$ & $1.250,3$ & \\
& & & 17,8 \\
4 & 731,6 & 400 & 10,6 \\
$4 \mathrm{~b}$ & 744,0 & 432,7 & 12,2 \\
& & & 13,3 \\
5 & 942,8 & 755,3 & 14,4 \\
$5 \mathrm{~b}$ & 930,8 & 745,3 & 12,2 \\
\hline 6 & 801,9 & 445,3 & \\
\hline
\end{tabular}

\section{Fundición nodular}

\begin{tabular}{llll}
$7^{*}$ & 720 & 720 & - \\
$7 b^{*}$ & 720 & 720 & - \\
& & & - \\
$8^{*}$ & 652 & 652 & - \\
$8 b^{*}$ & 652 & 652 & \\
& & & 3,9 \\
9 & 1.130 & 799,4 & 3,9 \\
$9 \mathrm{~b}$ & $1.145,3$ & 971,0 & \\
& & & 13,9 \\
10 & 545,9 & 415,7 & 15,6 \\
$10 \mathrm{~b}$ & 542,1 & 418,8 & 14,4 \\
& & & 18,3 \\
11 & 499,4 & 357,2 & 8,9 \\
$11 \mathrm{~b}$ & 489,3 & 325,8 & 10,0 \\
\hline 12 & & & 9,4 \\
$12 \mathrm{~b}$ & 708,2 & 427,0 & 8,3 \\
\hline 13 & & & \\
\hline $13 \mathrm{~b}$ & 735,8 & 459,1 &
\end{tabular}

Nota: Los datos de las probetas de referencia 1, 2, 7, 7b, 8 y $8 \mathrm{~b}$ marcadas con asterisco han sido tomados de la bibliografía, debido a la dificultad de mecanizar probetas Hounsfield $\mathrm{N}-13$ con estos materiales que presentan elevada dureza. Las referencias 3 y $3 b, 4$ y $4 b$ etc. se refieren a probetas en el mismo estado metalúrgico ensayadas por duplicado. Los autores no encuentran explicación a la dispersión de los resultados en los casos $3,3 b$ y $4,4 b$.
Tabla III. Resultados de los ensayos de dureza Table III. Hardness tests results

\begin{tabular}{crrr}
\hline Ref. & Dureza & Ref. & Dureza \\
\hline Acero & & & \\
\hline 1 & $60 \mathrm{HRC}$ & $1 \mathrm{~b}$ & $58 \mathrm{HRD}$ \\
2 & $55 \mathrm{HRC}$ & $2 \mathrm{~b}$ & $56 \mathrm{HRC}$ \\
3 & $41 \mathrm{HRC}$ & $3 \mathrm{~b}$ & $42 \mathrm{HRC}$ \\
4 & $97 \mathrm{HRB}$ & $4 \mathrm{~b}$ & $95 \mathrm{HRB}$ \\
5 & $91 \mathrm{HRB}$ & $5 \mathrm{~b}$ & $90 \mathrm{HRB}$ \\
6 & $94 \mathrm{HRB}$ & $6 \mathrm{~b}$ & $94 \mathrm{HRB}$ \\
& & & \\
\hline Fundición nodular & & \\
\hline 7 & $53 \mathrm{HRC}$ & $7 \mathrm{~b}$ & $55 \mathrm{HRC}$ \\
8 & $50 \mathrm{HRC}$ & $8 \mathrm{~b}$ & $50 \mathrm{HRC}$ \\
9 & $35 \mathrm{HRC}$ & $8 \mathrm{~b}$ & $34 \mathrm{HRC}$ \\
10 & $86 \mathrm{HRB}$ & $10 \mathrm{~b}$ & $86 \mathrm{HRB}$ \\
11 & $82 \mathrm{HRB}$ & $11 \mathrm{~b}$ & $82 \mathrm{HRB}$ \\
12 & $94 \mathrm{HRB}$ & $12 \mathrm{~b}$ & $96 \mathrm{HRB}$ \\
13 & $95 \mathrm{HRB}$ & $13 \mathrm{~b}$ & $95 \mathrm{HRB}$ \\
& & & \\
\hline
\end{tabular}

(espesor de $50 \mathrm{~mm}$ ). Ahora bien, los valores de KQ de la fundición 13 procedente de la sección gruesa son más altos que los de la fundición 12 , procedente de la sección delgada (Tabla IV).

Comparando los datos de tenacidad de fractura del acero con los de la fundición, se observa que los valores de tenacidad del acero son superiores a los correspondientes de la fundición en aquellas probetas que recibieron tratamiento de temple y revenido, y que presentan la misma tendencia a crecer conforme aumenta la temperatura de revenido hasta un máximo de $500^{\circ} \mathrm{C}$ para descender posteriormente hasta alcanzar $650^{\circ} \mathrm{C}$. Sin embargo, en el caso de las probetas en estado de moldeo, los datos son prácticamente iguales para acero y fundición, incluso es más alto el correspondiente a la fundición nodular de mayor tamaño de celda eutéctica (F-13).

La comparación entre los valores de resistencia de la fundición nodular y del acero al silicio muestra que todos los datos correspondientes a la primera están por debajo de los del acero. La evolución de la dureza con la temperatura de revenido de la fundición es similar a la de su correspondiente acero, siendo aproximadamente un $10 \%$ inferior; ahora bien, cuando se produce una matriz de martensita revenida, con el consiguiente incremento de dureza respecto a la que presenta en condición

Rev. Metal. Madrid 35 (1999)

http://revistademetalurgia.revistas.csic.es 

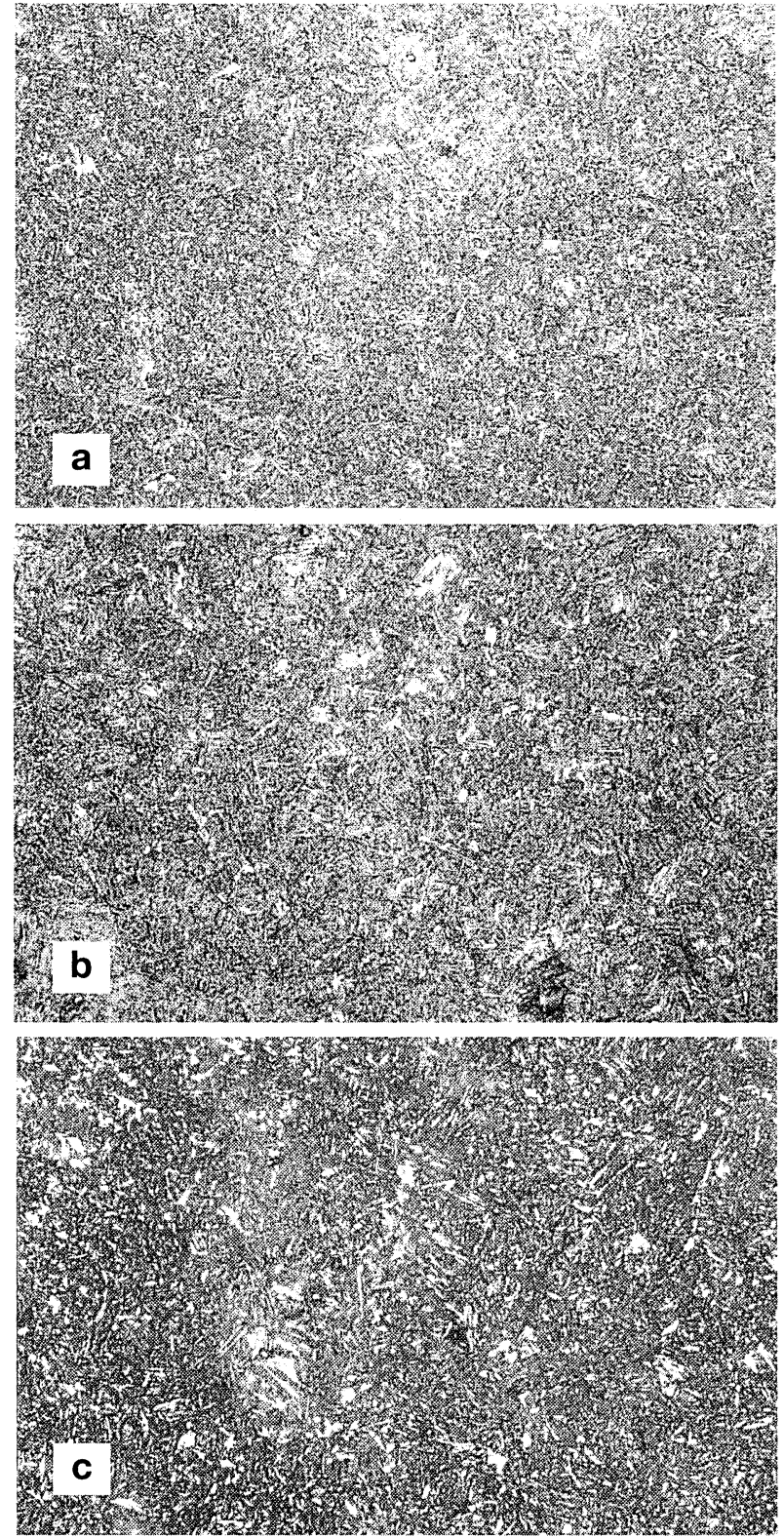
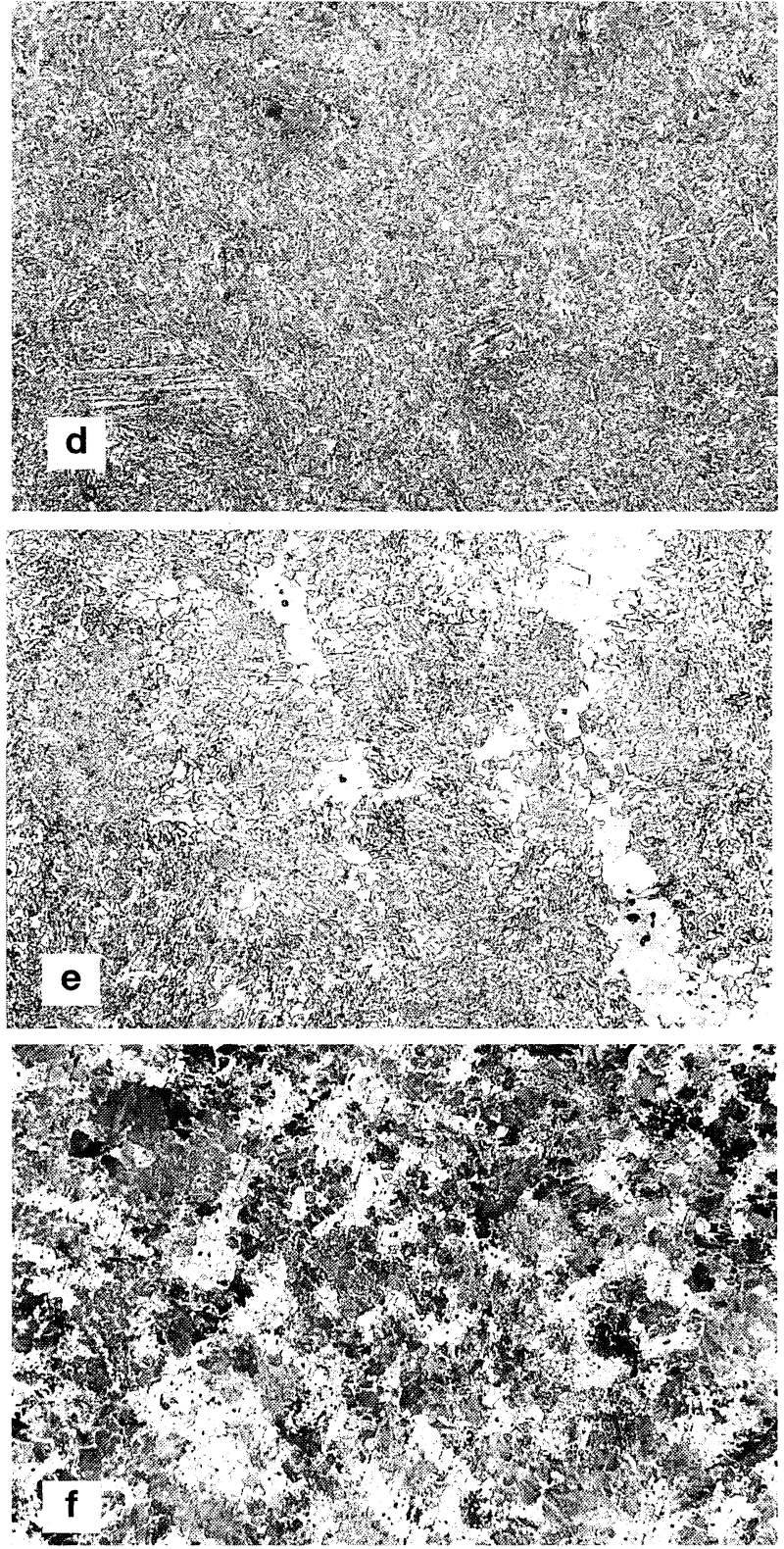

Figura 3. a) $A 1: \times 400$. b) A2: $\times 400$. c) A3: $\times 400$. d) A4: $\times 400$. e) A5: $\times 200$. f) A6: $\times 100$. (Reproducida en imprenta al $50 \%$ ).

Figure 3. a) A1: 400x. b) A2: 400x. c) A3: 400x. d) A4: 400x. e) A5: 200x. f) A6: 100x. (Printed reproduction at $50 \%$ ).

de moldeo, aquel no va acompañado de un aumento proporcional en la resistencia ni en la tenacidad.

La resistencia resulta ser muy sensible a los cambios de microestructura de la matriz, mientras que la modificación del tamaño de la celda eutéctica no origina más que un cambio modesto de la resistencia. La interpretación tradicional de la resistencia a la tracción supone que ésta viene determinada por la capacidad que presentan las ligaduras libres de grafito para soportar cargas. Si el ensayo de tracción es un proceso de fractura frágil, la resistencia a la tracción puede entonces interpretarse como una tensión de fractura crítica que es necesario alcanzar para propagar un defecto preexistente. Este concepto se aplica comúnmente para describir el comportamiento a la fractura de materiales cerámicos ${ }^{[3 \text { y } 4]}$.

Un examen detenido de la figura 2 revela que existe una relación directa entre dureza y resistencia para aquellas fundiciones nodulares cuyas matrices son más blandas ( $<35 \mathrm{HRC}$ ). Por el contrario, la fundición nodular de mayor dureza ( $>35$ HRC) muestra menor resistencia a la tracción. Así, la correlación resistencia-dureza no se da en el caso de la fundición nodular.

Los resultados relativos a la influencia del tamaño de celda eutéctica y microestructura de la matriz 

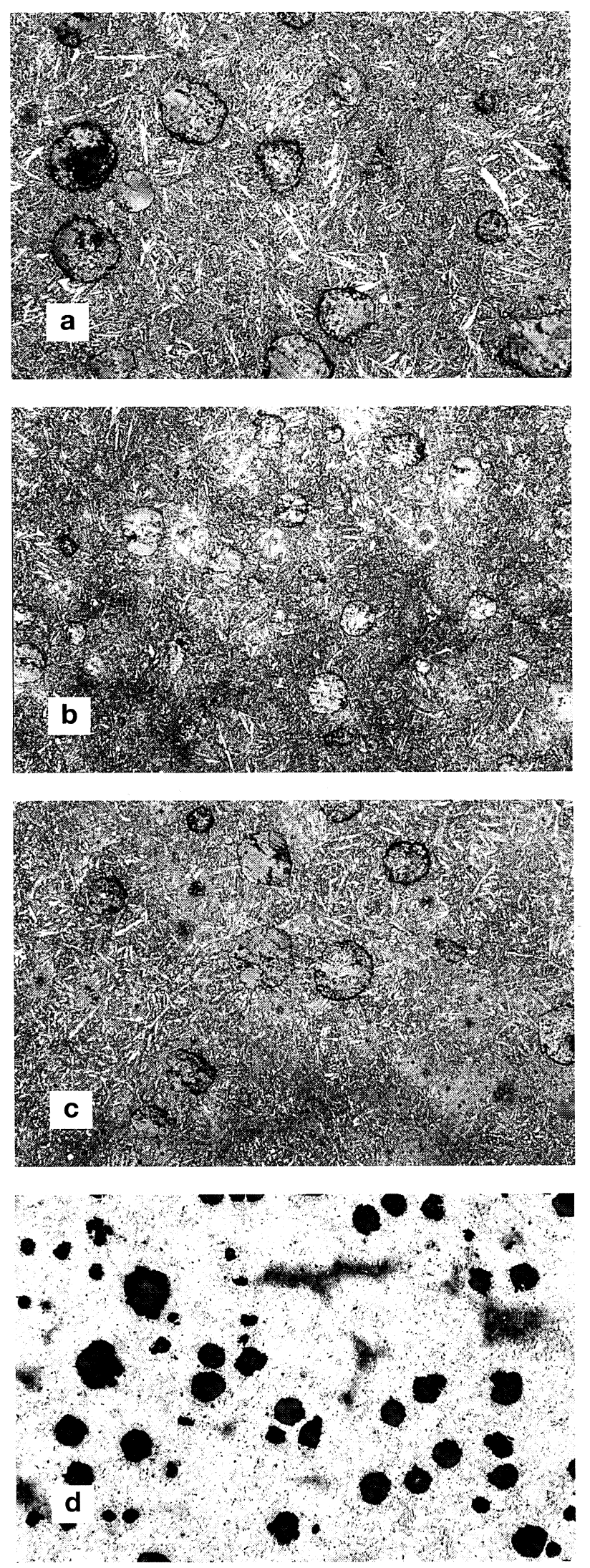

sobre la tenacidad de fractura están en buena concordancia con los de Castillo ${ }^{[2]}$. Un aspecto importante de los resultados presentados es que se demuestra que el efecto de los cambios microestructurales en los valores de $K_{\mathrm{Ic}}$ transcurre paralelamente con los cambios
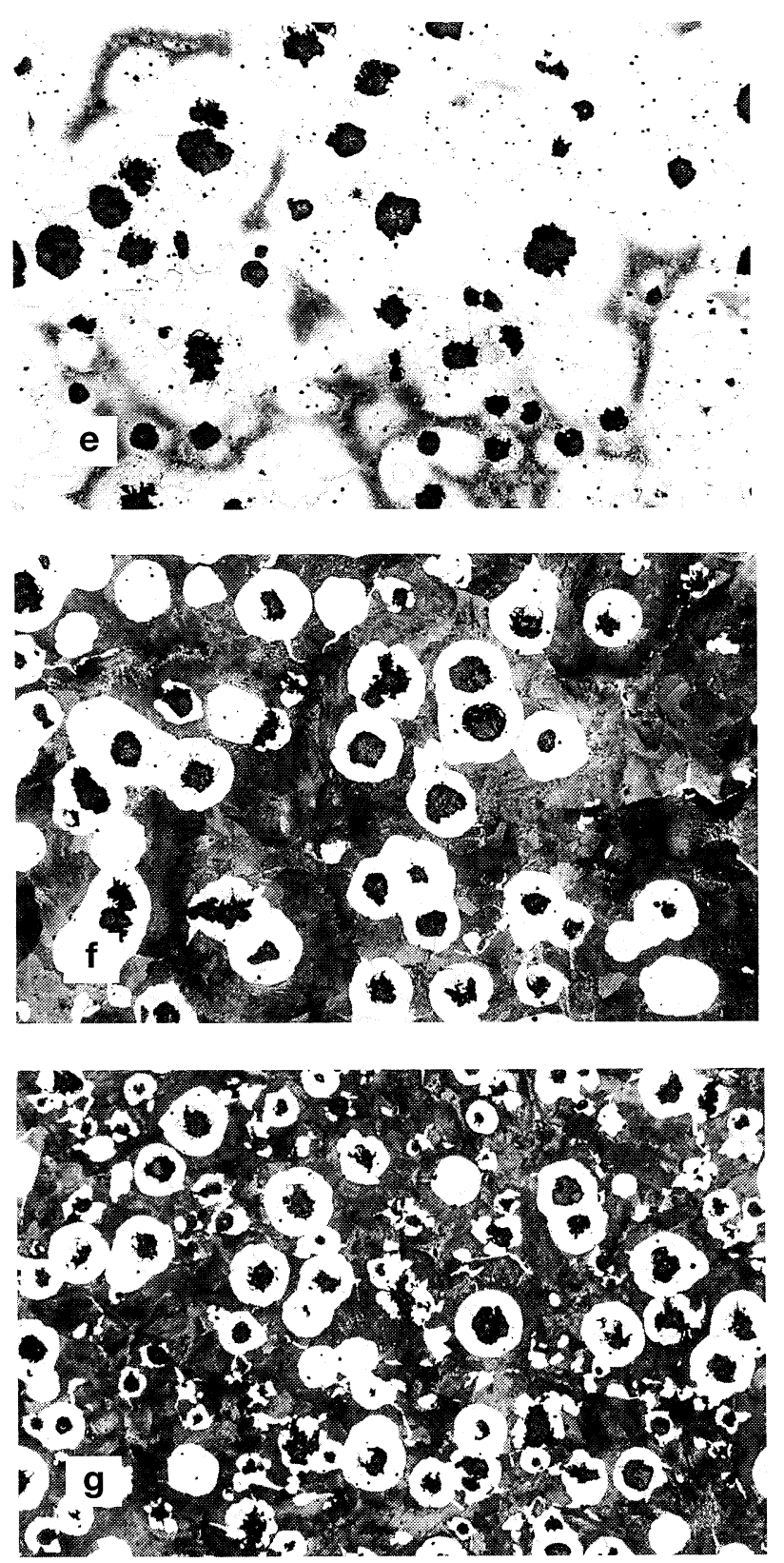

Figura 4. a) F7: $x 200$. b) F8: $x 200$. c) F9: $x 200$. d) F10: x100. e) F1 1: x100. f) F12: x100. g) F13: x100 (Reproducida en imprenta al $50 \%)$.

Figure 4. a) F7: 200x. b) F8: 200x. c) F9: 200x. d) F10: 100x. e) F11: 100x. f) F12: 100x. g) F13: 100 (Printed reproduction at $50 \%$ ).

de la resistencia a la tracción. Es sabido que en varios materiales metálicos no se observa relación directa entre resistencia a la tracción y $K_{\mathrm{Ic}}$.

En relación con el análisis fractográfico, la micrografía $5 \mathrm{~d}$, correspondiente al acero templado y revenido a $650^{\circ} \mathrm{C}$, muestra un caso de fractura dúctil de la matriz de martensita revenida que presenta hoyuelos formados por coalescencia de microhuecos. La misma figura muestra canales formados por coalescencia lineal de microhuecos junto con inclusiones alojadas en un hoyuelo de gran tamaño. 
Tabla IV. Resultados de los ensayos de tenacidad

Table IV. Toughness tests results

\begin{tabular}{|c|c|c|c|c|c|c|c|c|c|c|c|}
\hline Ref. & $\begin{array}{l}P_{\text {máx }} \\
(\mathrm{kN})\end{array}$ & $\begin{array}{c}P_{\mathrm{Q}} \\
(\mathrm{kN})\end{array}$ & $P_{\text {máx }} / P_{Q}$ & $a_{m} / W$ & $f(a / M)$ & $\begin{array}{c}K_{\mathrm{Q}} \\
\left(\mathrm{MPa} \cdot \mathrm{m}^{1 / 2}\right)\end{array}$ & $\begin{array}{c}K_{\text {máx }} \\
\left(\mathrm{MPa} \cdot \mathrm{m}^{1 / 2}\right)\end{array}$ & $\begin{array}{c}e_{\min } \\
(\mathrm{mm})\end{array}$ & $\begin{array}{c}K_{\mathrm{lc}} \\
\left(\mathrm{MPa} \cdot \mathrm{m}^{1 / 2}\right)\end{array}$ & $\begin{array}{c}R_{0,2} \\
(\mathrm{MPa})\end{array}$ & $R_{\mathrm{sb}}$ \\
\hline \multicolumn{12}{|l|}{ Acero } \\
\hline 1 & 10,9 & 10,9 & 1,0 & 0,409 & 2,03 & 54,5 & 54,5 & 2,43 & 54,5 & $1.750^{*}$ & 0,44 \\
\hline $1 b$ & 6,0 & 6,0 & 1,0 & 0,454 & 2,29 & 33,6 & 33,6 & 0,92 & 33,6 & $1.750^{*}$ & 0,28 \\
\hline 2 & 6,0 & 6,0 & 1,0 & 0,466 & 2,39 & 35,1 & 35,1 & 0,95 & 35,1 & $1.700^{*}$ & 0,30 \\
\hline \multicolumn{12}{|l|}{$2 b$} \\
\hline 3 & 14,5 & 14,5 & 1,0 & 0,466 & 2,39 & 85,1 & 85,1 & 25,1 & & 850,3 & 1,48 \\
\hline $3 b$ & & & & & & & & & & $1.250,3$ & \\
\hline 4 & 15,1 & 13,3 & 1,1 & 0,466 & 2,39 & 77,9 & 88,5 & 94,9 & & 400,0 & 3,28 \\
\hline $4 b$ & & & & & & & & & & 432,7 & \\
\hline 5 & 7,23 & 7,23 & 1,0 & 0,50 & 2,66 & 47,1 & 47,1 & 9,7 & 47,1 & 755,3 & 0,94 \\
\hline $5 b$ & 7,5 & 7,5 & 1,0 & 0,477 & 2,50 & 45,9 & 45,9 & 9,4 & 45,9 & 745,3 & 0,91 \\
\hline 6 & 8,6 & 6,9 & 1,2 & 0,466 & 2,39 & 40,4 & 40,4 & 18,3 & & 445,3 & 1,49 \\
\hline $6 b$ & 7,7 & 7,7 & 1,0 & 0,466 & 2,39 & 45,1 & 45,1 & 24,1 & & 458,5 & 1,37 \\
\hline
\end{tabular}

Fundición nodular

\begin{tabular}{cccccccccccc}
\hline 7 & 4,92 & 4,92 & 1,0 & 0,409 & 2,03 & 24,4 & 24,4 & 2,8 & 24,4 & $720^{*}$ & 0,48 \\
$7 \mathrm{~b}$ & & & & & & & & & & & \\
8 & & & & & & & & & & \\
83 & 5,33 & 1,0 & 0,454 & 2,32 & 30,3 & 30,3 & 5,4 & 30,3 & $652^{*}$ & 0,68 \\
$8 \mathrm{~b}$ & 5,4 & 5,4 & 1,0 & 0,443 & 2,25 & 29,8 & 29,8 & 5,2 & 29,8 & $652^{*}$ & 0,66 \\
9 & 8,57 & 8,57 & 1,0 & 0,477 & 2,50 & 52,5 & 52,5 & 10,8 & 52,5 & 799,4 & 0,97 \\
$9 \mathrm{~b}$ & 8,5 & 8,5 & 1,0 & 0,466 & 2,39 & 49,9 & 49,9 & 9,7 & 49,9 & 971,0 & 0,76 \\
10 & 8,4 & 7,9 & 1,0 & 0,466 & 2,39 & 46,2 & 49,2 & 30,9 & & 415,7 & 3,29 \\
$10 \mathrm{~b}$ & 8,8 & 8,2 & 1,0 & 0,466 & 2,39 & 48,2 & 51,7 & 33,1 & & 418,8 & 1,81 \\
11 & 8,1 & 7,7 & 1,0 & 0,472 & 2,44 & 46,2 & 48,6 & 41,8 & & 357,2 & 2,03 \\
$11 \mathrm{~b}$ & $*$ & & & & & & & & 325,8 & \\
12 & 7,3 & 7,3 & 1,0 & 0,454 & 2,32 & 41,5 & 41,5 & 29,8 & & 379,9 & 1,60 \\
$12 \mathrm{~b}$ & 7,6 & 7,6 & 1,0 & 0,454 & 2,32 & 43,2 & 43,2 & 25,6 & & 427,0 & 1,47 \\
13 & 9,2 & 8,5 & 1,0 & 0,482 & 2,53 & 52,7 & 57,0 & 45,7 & & 389,9 & 2,17 \\
$13 \mathrm{~b}$ & 8,1 & 8,1 & 1,0 & 0,50 & 2,66 & 53,0 & 53,0 & 33,4 & & 459,1 & 1,75 \\
\hline
\end{tabular}

Nota: Los datos de límite elástico y resistencia a tracción de las probetas de referencia 1, 1b, 2, 7, 8 y $8 \mathrm{~b}$ marcadas con asterisco han sido tomados de la bibliografía, debido a la dificultad de mecanizar probetas Hounsfield $\mathrm{N}-13$ con estos materiales que presentan elevada dureza.

En las figuras $5 \mathrm{a}, 5 \mathrm{~b}$, y $5 \mathrm{c}$ también se aprecian hoyuelos en una gran variedad de tamaños, así como inclusiones no metálicas (probablemente de sulfuro de manganeso) alojadas en algunos de ellos, lo cual prueba que las inclusiones son una de las causas de formación de hoyuelos. Sin embargo, la mayor parte de la superficie contiene también facetas pequeñas, originadas aparentemente por clivaje. En la micrografía 5e se aprecian claramente los dos modos de fractura (hoyuelos y clivaje) correspondientes a la fractura dúctil de una región ferrítica del acero al silicio recocido (parte clara) y a la fractura por clivaje que presenta "marcas o huellas fluviales" características de la fractura frágil de perlita.

La fundición sometida a tratamiento de recocido (Fig. 6e) muestra una superficie característica 

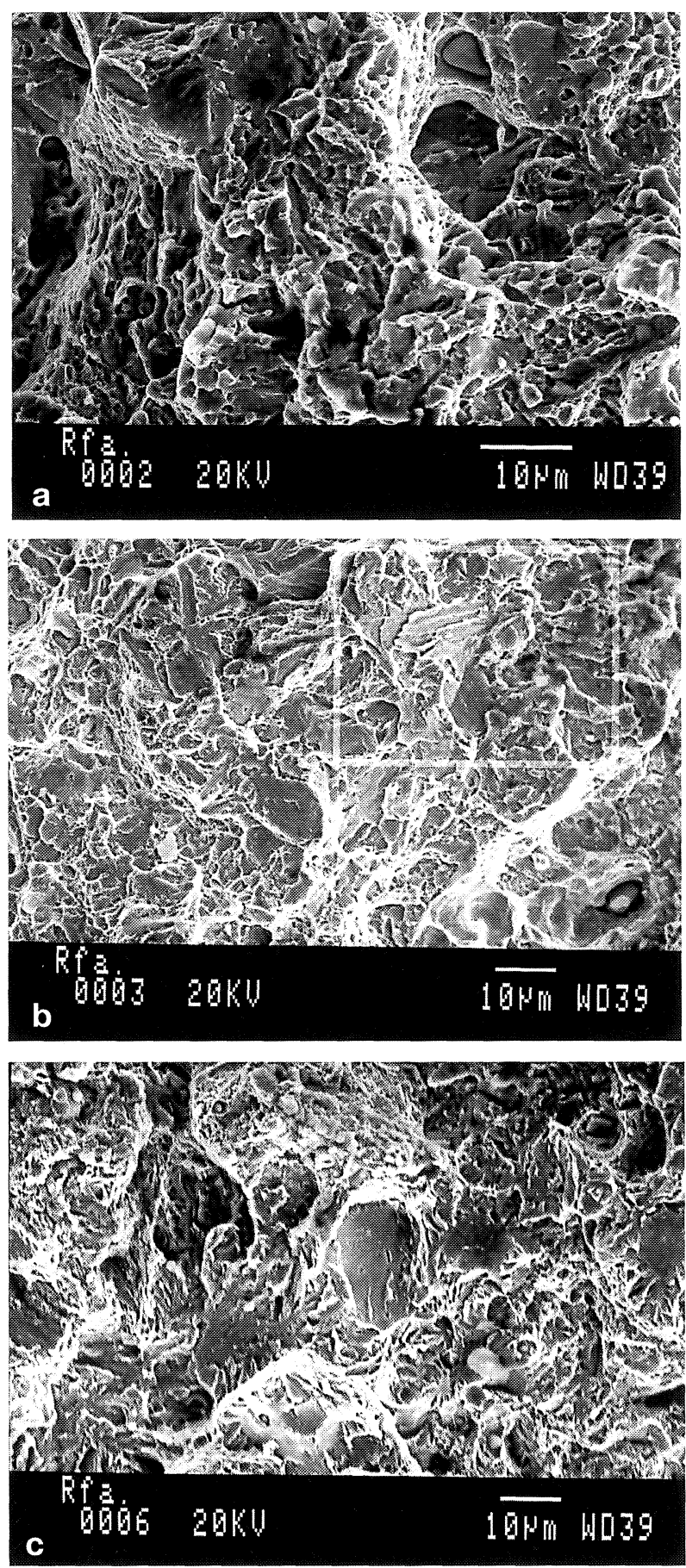

de fractura dúctil ya que aparece gran cantidad de hoyuelos. Por otra parte, también se aprecia la presencia de zonas más planas y huellas fluviales características de la fractura por cuasi clivaje, más propio de roturas frágiles. Así, se puede atribuir al tratamiento de recocido la presencia de gran cantidad de ferrita, la cual va asociada a la presencia de cavidades y, en consecuencia, a fractura dúctil, mientras que las pequeñas regiones perlíticas van asociadas a la rotura frágil.

Las micrografías of y $6 \mathrm{~g}$, correspondientes a fundición en estado de moldeo, muestran principalmente un modo de rotura por clivaje o exfoliación
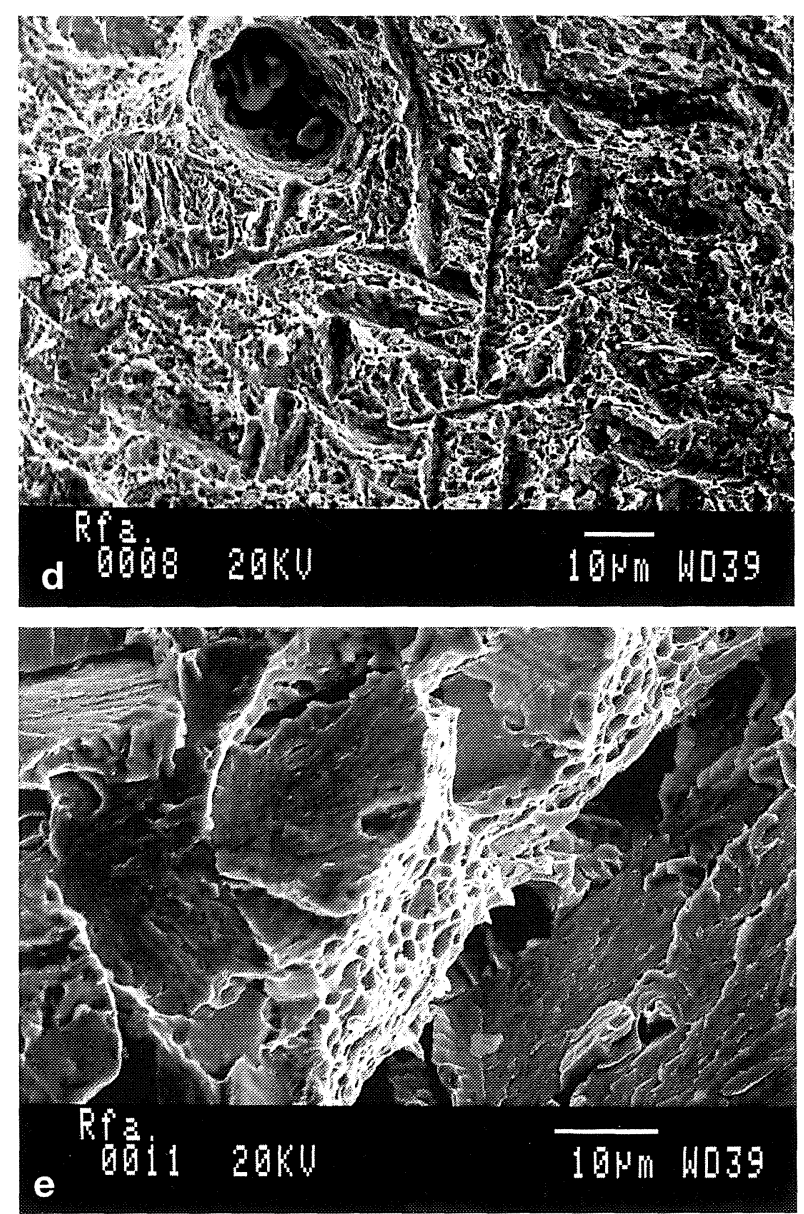

Figura 5. Superficie de fractura después del ensayo ASTM E 399 de: a) A1. b) A2. c) A3. d) A4. e) A5.

Figure 5. Typical area of fracture surface after ASTM E 399 test of: a) A1. b) A2. c) A3. A4. e) A5.

Tabla V. Resultados de los ensayos Charpy Table V. Charpy tests results

\begin{tabular}{|c|c|c|c|c|c|}
\hline \multirow[t]{2}{*}{ Ref. } & \multirow[t]{2}{*}{ Condición } & \multicolumn{4}{|c|}{ Energía $\left(\mathrm{J} / \mathrm{cm}^{2}\right)$} \\
\hline & & $26^{\circ} \mathrm{C}$ & $-10^{\circ} \mathrm{C}$ & $-30^{\circ} \mathrm{C}$ & $-60^{\circ} \mathrm{C}$ \\
\hline \multicolumn{6}{|l|}{ Acero } \\
\hline 1 & $\mathrm{~T}-\mathrm{R} 200^{\circ} \mathrm{C}$ & 10 & - & 7,5 & 6,2 \\
\hline 2 & $\mathrm{~T}-\mathrm{R} 350^{\circ} \mathrm{C}$ & 10 & - & 6,2 & 6,2 \\
\hline 3 & $\mathrm{~T}-\mathrm{R} 500{ }^{\circ} \mathrm{C}$ & 12,5 & 12,5 & 16,2 & 10,0 \\
\hline 4 & $\mathrm{~T}-\mathrm{R} 650^{\circ} \mathrm{C}$ & 35,0 & 20,0 & 17,5 & 15,0 \\
\hline 5 & Recocido & 6,3 & 7,5 & 5,0 & 5,0 \\
\hline 6 & Moldeo & 8,8 & 8,8 & 7,5 & 3,7 \\
\hline \multicolumn{6}{|c|}{ Fundición nodular } \\
\hline 7 & T-R $200^{\circ} \mathrm{C}$ & 6,3 & - & - & 5,0 \\
\hline 8 & $\mathrm{~T}-\mathrm{R} 350^{\circ} \mathrm{C}$ & 5,0 & - & 3,7 & 5,0 \\
\hline 9 & T-R $500^{\circ} \mathrm{C}$ & 6,3 & 7,5 & 5,0 & 5,0 \\
\hline 10 & $\mathrm{~T}-\mathrm{R} 650^{\circ} \mathrm{C}$ & 12,5 & 11,3 & 12,5 & 12,5 \\
\hline 11 & Recocido & 10,0 & 7,5 & 5,0 & 5,0 \\
\hline 12 & Moldeo & 6,3 & 6,3 & 5,0 & 5,0 \\
\hline 13 & Moldeo & 7,5 & 6,3 & 5,0 & 5,0 \\
\hline
\end{tabular}

Nota: La causa de no haber realizado ensayos en algunas probetas es no haber conseguido mecanizar la entalla de las mismas. 
Tabla VI. Variables microestructurales de la fundición nodular en condición de moldeo

Table VI. Microstructural parameters in as-cast nodular iron

\begin{tabular}{lccccc}
\hline \multicolumn{1}{c}{ Referencia } & $\begin{array}{c}\text { Espesor } \\
\text { sección } \\
(\mathrm{mm})\end{array}$ & $\begin{array}{c}\text { Tamaño } \\
\text { de celda } \\
(\mathrm{mm})\end{array}$ & $\begin{array}{c}\text { Forma } \\
\text { del } \\
\text { grafito }\end{array}$ & $\begin{array}{c}\text { Distribución } \\
\text { del } \\
\text { grafito }\end{array}$ & $\begin{array}{c}\text { Tamaño } \\
\text { del } \\
\text { grafito }\end{array}$ \\
\hline Fundición nodular sección delgada (ND) & 14 & 0,10 & $\mathrm{VI}$ & $\mathrm{A}$ & 5 \\
Fundición nodular sección gruesa (NG) & 50 & 0,13 & $\mathrm{VI}$ & $\mathrm{A}$ & 5 \\
\hline
\end{tabular}

Tabla VII. Microestructuras del acero al silicio y de la fundición nodular

Table VII. Microstructural parameters in as-cast nodular iron

\begin{tabular}{|c|c|c|c|}
\hline Material & Condición & Matriz & Grafito \\
\hline \multicolumn{4}{|l|}{ Acero } \\
\hline 1 & $\mathrm{~T}-\mathrm{R} 200^{\circ} \mathrm{C}$ & Martensita revenida fina & \\
\hline 2 & $\mathrm{~T}-\mathrm{R} 350^{\circ} \mathrm{C}$ & Martensita revenida con colonias bainíticas & \\
\hline 3 & $\mathrm{~T}-\mathrm{R} 500^{\circ} \mathrm{C}$ & Martensita revenida y bainita & \\
\hline 4 & $\mathrm{~T}-\mathrm{R} 650^{\circ} \mathrm{C}$ & Martensita evenida y bainita & \\
\hline 5 & Recocido & Ferrita (40\%) y perlita ligeramente globular (60\%) & \\
\hline 6 & Moldeo & Ferrita (45\%) y perlita (55\%) & \\
\hline \multicolumn{4}{|c|}{ Fundición nodular } \\
\hline 7 & $\mathrm{~T}-\mathrm{R} 200^{\circ} \mathrm{C}$ & Martensita revenida grosera & VI A 4-5 \\
\hline 8 & $\mathrm{~T}-\mathrm{R} 350^{\circ} \mathrm{C}$ & Martensita revenida grosera & VI A 4-5 \\
\hline 9 & $\mathrm{~T}-\mathrm{R} 500^{\circ} \mathrm{C}$ & Martensita revenida grosera & VI A 4 \\
\hline 10 & $\mathrm{~T}-\mathrm{R} 650^{\circ} \mathrm{C}$ & Ferrita (95 \%) y cementita (5 \%) & VI A 4-5 \\
\hline 11 & Recocido & Ferrita (90\%) y perlita (10\%) & VIA 4 \\
\hline 12 & Moldeo (N.D.) & Ferrita (30 \%) y perlita (70 \%) & VIA 5 \\
\hline 13 & Moldeo (N.G.) & Ferrita (30 \%) y perlita (70 \%) & VI A 5-6 \\
\hline
\end{tabular}

característico de superficies de fractura frágiles y propio de matrices que contienen una proporción elevada de perlita en su matriz. La fundición templada y revenida a $650^{\circ} \mathrm{C}$ (Fig. $6 \mathrm{~d}$ ) revela una superficie de fractura de gran rugosidad asociada a una considerable plasticidad de la matriz, por lo que se puede considerar un caso de fractura dúctil. Las micrografías 6 a y $6 \mathrm{~b}$, correspondientes a fundición nodular templada y revenida a 200 y $350{ }^{\circ} \mathrm{C}$ respectivamente, muestran superficies de fractura frágil con regiones planas, en donde se ha producido la separación de material propia del clivaje, es decir, según planos cristalográficos.

En la tabla IX se resume el efecto del tratamiento en el modo de fractura de la fundición y del acero. En este último se observan dos modos de fractura; el modo fibroso, asociado a las dos muestras de menor dureza y el modo de clivaje propio de las muestras templadas y revenidas a 200 y $350^{\circ} \mathrm{C}$. Este último modo también se observa en la muestra de baja dureza de acero recocido cuya matriz contiene $60 \%$ de perlita. Las piezas de fundición nodular muestran unos modos de fractura para cada tratamiento iguales a los de su correspondiente acero, es decir, fibroso en las tratadas a 350 y $650^{\circ} \mathrm{C}$ y frágil en las más duras (tratadas a 200 y $350^{\circ} \mathrm{C}$ ). La muestra más blanda, recocida, que contiene un $90 \%$ de ferrita muestra, al contrario que la de acero, un modo de fractura fibroso. Finalmente, la superficie de fractura de la pieza de moldeo, que contiene un $70 \%$ de perlita, muestra un modo de clivaje frágil.

Es difícil generalizar el comportamiento en fractura de los aceros debido a la complejidad de los micromecanismos; por ello, la discusión que sigue se basa en las relaciones observadas más comúnmente entre modo de fractura y resistencia de la matriz. En general, existe una relación inversa 

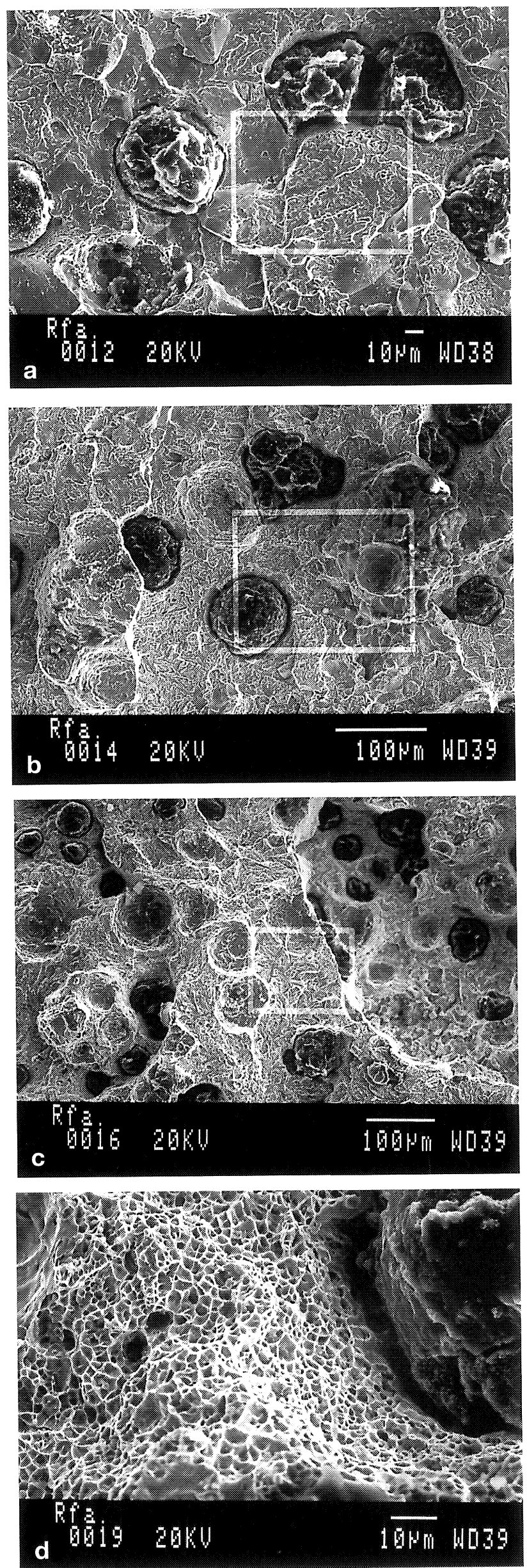
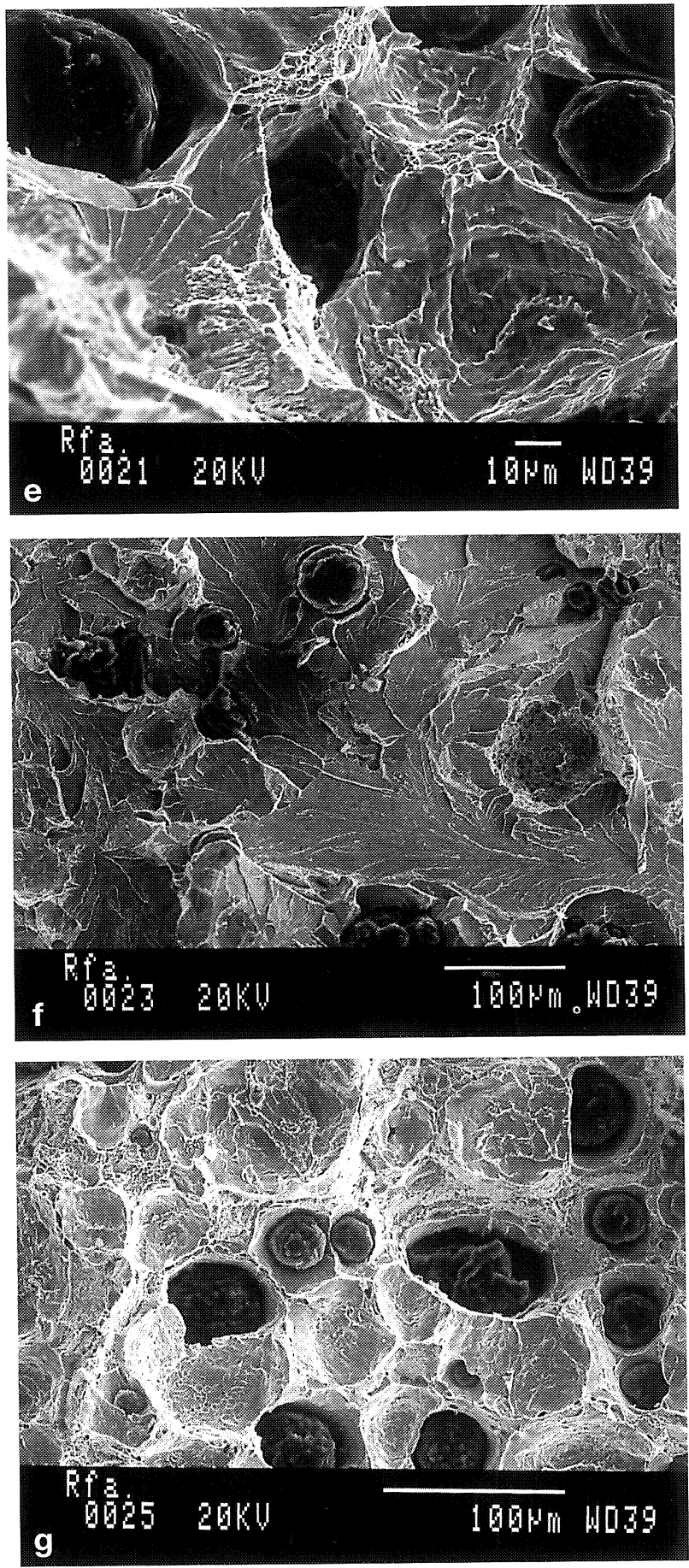

Figura 6. Superficie de fractura después del ensayo ASTM E 399 de: a) F7. b) F8. c) F9. d) F10. e) F11. f) F12. g) F13.

Figure 6. Typical area of fracture surface after ASTM E 399 test of: a) F7. b) F8. c) F9. d) F10. e) F11. f) F12. g) F13.

entre $K_{\mathrm{Ic}}$ y resistencia a la tracción o dureza; así, por ejemplo, los aceros de alta resistencia se asocian a bajos valores de $K_{\mathrm{Ic}}$ y los aceros de baja resistencia a valores altos de $K_{\mathrm{Ic}}$. Existen dos razones principales para explicar este comportamiento; en primer lugar, conforme crece la resistencia, tienden a estimularse o a reforzarse los modos de fractura frágiles tales como clivaje o separación intergranular, ya que dependen de valores críticos de

Rev. Metal. Madrid 35 (1999) 
Tabla VIII. Efecto de las variables microestructurales sobre las propiedades mecánicas

Table VIII. Effect of microstructural parameters on mechanical properties

\begin{tabular}{|c|c|c|c|c|c|c|c|}
\hline \multirow{2}{*}{ Ref. } & \multirow{2}{*}{ Condición } & \multirow{2}{*}{ Microestructuras } & \multicolumn{2}{|c|}{ Dureza } & \multirow{2}{*}{$\begin{array}{c}R_{\mathrm{m}} \\
(\mathrm{MPa})\end{array}$} & \multirow[t]{2}{*}{$K_{\mathrm{lc}}$} & \multirow{2}{*}{$\begin{array}{c}K_{\mathrm{Q}} \\
\left(\mathrm{MPa} \cdot \mathrm{m}^{1 / 2}\right)\end{array}$} \\
\hline & & & HRC & HRB & & & \\
\hline \multicolumn{8}{|l|}{ Acero } \\
\hline 1 & T-R 200 & Martensita revenida fina & 60 & & 2.300 & $54,5^{*}$ & 54,5 \\
\hline $1 b$ & & & 58 & & 2.300 & 33,6 & 33,6 \\
\hline 2 & T-R 350 & Martensita revenida fina & 55 & & 2.000 & 35,1 & 35,1 \\
\hline $2 b$ & & con colonias bainíticas & 56 & & 2.000 & & \\
\hline 3 & T-R 500 & Martensita revenida y bainita & 41 & & $1.310,1$ & & 85,1 \\
\hline $3 b$ & & & 42 & & $1.371,7$ & & \\
\hline 4 & T-R 650 & Martensita revenida y bainita & & 96 & 731,6 & & 77,9 \\
\hline $4 b$ & & & & 96 & 744,0 & & \\
\hline 5 & Recocido & Ferrita (40 \%) y perlita & & 91 & 942,8 & 47,1 & 47,1 \\
\hline $5 b$ & & ligeramente globular (60\%) & & 90 & 930,8 & 45,9 & 45,9 \\
\hline 6 & Moldeo & Ferrita (45 \%) y perlita (55 \%) & & 94 & 801,9 & & 40,4 \\
\hline $6 b$ & & & & 94 & 812,0 & & 45,1 \\
\hline \multicolumn{8}{|c|}{ Fundición nodular } \\
\hline 7 & T-R 200 & Matriz: Martensita revenida & 53 & & 720 & & 24,4 \\
\hline $7 b$ & & grosera. Grafito VI A 4-5 & 55 & & 720 & & \\
\hline 8 & T-R 350 & Matriz: Martensita revenida & 50 & & 652 & & 30,3 \\
\hline $8 b$ & & grosera. Grafito VI A 4-5 & 50 & & 652 & & 29,8 \\
\hline 9 & T-R 500 & Matriz: Martensita revenida & 35 & & $1.130,2$ & 52,5 & 52,5 \\
\hline $9 b$ & & grosera. Grafito VI A 4. Tamaño & 34 & & $1.145,3$ & 49,9 & 49,9 \\
\hline 10 & T-R 650 & Matriz: Ferrita (95 \%) y cementita & & 86 & 545,9 & & 46,2 \\
\hline $10 \mathrm{~b}$ & & (5 \%). Grafito VI A 4-5 & & 86 & 542,1 & & 48,2 \\
\hline 11 & Recocido & Matriz: Ferrita (90 \%) y perlita & & 82 & 499,4 & & 46,2 \\
\hline $11 b$ & & (10\%). Grafito VI A 4. & & 82 & 489,3 & & \\
\hline 12 & Moldeo. Sección & Matriz: Ferrita (30 \%) y perlita & & 94 & 688,7 & & 41,5 \\
\hline $12 b$ & $\begin{array}{l}\text { delgada. Tamaño } \\
\text { de celda: } 0,10 \mathrm{~mm}\end{array}$ & (70\%). Grafito VI A 4-5 & & 96 & 708,2 & & 43,2 \\
\hline 13 & Moldeo. Sección & Matriz: Ferrita (30 \%) y perlita & & 95 & 692,4 & & 52,7 \\
\hline $13 b$ & $\begin{array}{l}\text { gruesa. Tamaño } \\
\text { de celda: } 0,13 \mathrm{~mm}\end{array}$ & (70 \%). Grafito VI A 5-6 & & 95 & 735,8 & & \\
\hline
\end{tabular}

* Valor obtenido sin preagrietamiento por fatiga.

resistencia; en segundo lugar, se localiza más la plasticidad en la punta de la grieta. Esto último origina una disminución de tenacidad ya que durante la deformación plástica se absorbe una gran cantidad de energía.

Los modos frágiles de fractura tales como clivaje transgranular o separación intergranular se encuentran asociados normalmente a valores bajos de $K_{\mathrm{Ic}}$, mientras que el modo de fractura fibroso está asociado generalmente a valores relativamen- te altos $K_{\text {Ic }}$. Se da fractura por clivaje en aceros suaves cuando la tensión principal máxima de tracción alcanza un valor crítico, conocido como tensión de fractura por clivaje $S_{f}$.

Varios investigadores, Knott ${ }^{[5]}$, Ritchie ${ }^{[6]}$ y Curry $^{[7]}$, han medido la tensión de fractura por clivaje de aceros suaves ensayando por doblado barras con entalla a temperaturas criogénicas. Se ha demostrado que $S_{f}$ depende del tamaño de grano, alcanzando valores más altos cuanto más fino es 
aquel. Habitualmente, las partículas de carburo actúan como núcleo de iniciación de las grietas de clivaje.

El proceso de fractura fibrosa consiste en la nucleación de huecos sobre partículas tales como inclusiones o carburos con posterior crecimiento y coalescencia por medio de un mecanismo de estrechamiento interno. El acero muestra un paralelismo entre resistencia, dureza y tenacidad, de modo que mientras resistencia y dureza discurren paralelas, la tenacidad lo hace de manera inversa (Fig. 2).

En el caso de la fundición nodular, los mecanismos de fractura son iguales que los del correspondiente acero (Tabla IX). Las observaciones microestructurales indican que el micromecanismo de fractura implica el enlace de microgrietas nucleadas en grafito mediante regiones de matriz deformada plásticamente. Precisamente, la baja resistencia de la matriz estimula la deformación plástica, lo cual facilita el mecanismo de fractura fibroso. Dado que este último ocurre mediante un mecanismo controlado por la deformación, casi toda la energía se consume en la deformación plástica del ligamento matriz.

Normalmente, los aceros presentan una tensión de fractura por clivaje más elevada que el límite elástico uniaxial. En consecuencia, puede darse clivaje a temperatura ambiente solamente bajo un estado de tensiones triaxial, tal como se desarrolla en ensayos con entalla. En el caso de las fundiciones, el mecanismo de fractura es similar al que sucede en aceros cuando se alcanza un nivel suficiente de dureza en la matriz, tal como en las estructuras de martensita revenida, pudiendo darse modos frágiles de fractura incluso bajo un grado de triaxialidad. de tensiones moderado. Bajo estas condiciones, el modo de fractura de la matriz de fundición es el mismo que el del acero sometido a similares condiciones de tratamiento térmico, es decir separación intergranular. En esta investigación se observaron fracturas intergranulares en ambos materiales cuando presentaron martensita revenida.

\section{CONCLUSIONES}

Se ha observado que en fundiciones de un determinado tamaño de celda eutéctica los cambios en la microestructura conducen a variaciones similares en la resistencia a la tracción y en $K_{\mathrm{Ic}}$. Esto sugiere que la resistencia a la tracción está controlada por el $K_{\text {Ic }}$ y el tamaño de defecto, que depende a su vez de la morfología del grafito.

En general, la fundición nodular no muestra una correlación clara entre resistencia a la tracción y dureza, siendo esta última una medida de la resistencia de la matriz.

La resistencia de la matriz de fundición nodular y dél acero al silicio influye en el micromecanismo de separación de la matriz.

La fundición nodular, cuya matriz presenta baja resistencia, es susceptible de fractura fibrosa, mientras que la de alta resistencia experimenta fractura intergranular, actuando de igual manera que el acero al silicio. Cuando la matriz de fundición nodular se separa mediante un mecanismo fibroso existe una relación directa entre dureza de la matriz, factor $K_{\mathrm{Ic}}$ y resistencia a la tracción de la fundición. Cuando la matriz de fundición nodular falla de manera frágil existe una correlación inversa entre dureza de la matriz, factor $K_{\mathrm{Ic}}$ y resistencia a la tracción de la fundición.

En lo relativo a los ensayos de impacto se observa un paralelismo en el comportamiento entre el acero al silicio y la fundición nodular, de manera que a mayor temperatura de revenido, mayor es

Tabla IX. Efecto del tratamiento en el modo de fractura de la fundición nodular y del acero al silicio

Table IX. Effect of heat treatment on the fracture mode of nodular iron and silicon steel

\begin{tabular}{|c|c|c|c|c|c|}
\hline \multirow[t]{2}{*}{$\begin{array}{c}\text { Tratamiento térmico } \\
\text { o estado }\end{array}$} & \multirow[t]{2}{*}{$\begin{array}{l}\text { Microestructura } \\
\text { de la matriz }\end{array}$} & \multicolumn{2}{|c|}{ Dureza } & \multicolumn{2}{|c|}{$\begin{array}{l}\text { Modo predominante de } \\
\text { fractura de la matriz }\end{array}$} \\
\hline & & Fundición & Acero & Fundición & Acero \\
\hline Recocido & Ferrita y perlita & $82 \mathrm{HRB}$ & $90 \mathrm{HRG}$ & Fibroso & Clivaje \\
\hline Moldeo & Ferrita y perlita & $86 \mathrm{HRB}$ & $94 \mathrm{HRB}$ & Clivaje & - \\
\hline Temple y revenido a $200{ }^{\circ} \mathrm{C}$ & Martensita revenida & $54 \mathrm{HR}$ & $59 \mathrm{HRC}$ & Clivaje & Clivaje \\
\hline Temple y revenido a $350^{\circ} \mathrm{C}$ & Martensita revenida & $50 \mathrm{HRC}$ & $55 \mathrm{HRC}$ & Clivaje & Clivaje \\
\hline Temple y revenido a $500{ }^{\circ} \mathrm{C}$ & Martensita revenida & $34 \mathrm{HRC}$ & $41 \mathrm{HRC}$ & Fibroso & Fibroso \\
\hline Temple y revenido a $650^{\circ} \mathrm{C}$ & Martensita revenida & 86 HRB & $96 \mathrm{HRB}$ & Fibroso & Fibroso \\
\hline
\end{tabular}


la energía de impacto. Ahora bien, mientras el acero al silicio incrementa notablemente sus valores de energía de impacto Charpy, cuando se le da un tratamiento de temple y revenido, frente a los valores que presenta en condición de moldeo o de recocido, la fundición nodular presenta valores de energía de impacto en condición de moldeo y recocido similares a los de temple y revenido excepto en el caso de T-R a $650^{\circ} \mathrm{C}$.

Si se comparan los resultados de los ensayos de Charpy con los de tenacidad de fractura se observa que a temperatura ambiente, tanto los del acero como los de la fundición aumentan con la temperatura de revenido hasta un máximo en aquellas probetas revenidas a $650^{\circ} \mathrm{C}$, pero en los valores de $K_{\mathrm{Ic}}$ alcanzan su máximo en probetas revenidas a $500{ }^{\circ} \mathrm{C}$ decreciendo seguidamente para las revenidas a $650^{\circ} \mathrm{C}$. Así pues, no se da una correlación definida entre ambos parámetros indicadores de la tenacidad de los materiales.

\section{REFERENCIAS}

[1] J.D. MURO y F.J. Solana, Tenacidad de fractura de la fundición dúctil, Trabajo de fin de carrera, Universidad de Zaragoza, 1994.

[2] R.N. CASTILO, A fracture mechanics study of flake graphite cast iron, Tesis, Universidad de Londres, 1985.

[3] A.G. Evans y G. Tappin, Proc. Brit. Ceram. Soc. 20 (1972) 275.

[4] B.J. Dalgleish y P.L. Prat, Proc. Brit. Ceram. Soc. 25 (1975) 295.

[5] J.F. KNOT, Iron Steel Inst. 204 (1966) 144.

[6] R.O. RITCHIE, J.F. KNOTT y J.R. RICE, J. Mech. Phys. Solids. 21 (1973) 395.

[7] D.A. CURRY y J.F. KNOT, Met. Sci. 13 (1979) 341. 